\title{
EFFECT OF PAROXETINE IN ANXIETY DISORDER AMONG SCHOOL DROPOUT TEENAGER IN SOUTH INDIAN POPULATION
}

\author{
PADMA PRIYA CHANDRAN ${ }^{1}$, SINDHU S. ${ }^{2}$, NAVANEETHAKRISHNAN S. ${ }^{2}$, SASIKUMAR S. ${ }^{2}$, KARTHIK S. ${ }^{3 *}$
}

${ }^{1}$ Consultant, Department of Psychiatry, Sri Ramachandra Institute of Higher Education and Research (DU), Porur 600116, ${ }^{2}$ Pharm D 5 Year Students, Faculty of Pharmacy, Sri Ramachandra Institute of Higher Education and Research (DU), Porur 600116, ${ }^{* 3}$ Faculty of Pharmacy, Sri Ramachandra Institute of Higher Education and Research (DU), Porur 600116 Email: karthiksjn19@gmail.com

Received: 07 Apr 2020, Revised and Accepted: 21 May 2020

\begin{abstract}
Objective: Anxiety disorders are the most common group of psychiatric illnesses in children. This study is to observe the effectiveness of Paroxetine in anxiety disorder among teenagers in South India population using Hamilton Anxiety Rating Scale (HAM-A) and to screen the possible risk for paroxetine in anxiety disorder among teenagers.
\end{abstract}

Methods: This study is a prospective observational study that was conducted for a period of 6 mo. Of 84 teenage patients with anxiety disorder assessed using Hamilton Anxiety Rating Scale (HAM-A) were followed-up in an outpatient psychiatric ward. Study population includes both sexes, age group between 13 to $19 \mathrm{y}$, Teenage patient receiving paroxetine for anxiety disorder were included and patients unwilling to give written informed consent or assent form were excluded.

Results: Out of 84 patients the prevalence of symptoms before the drug treatment, 65 patients were falling in very severe category, which was assessed by HAM-A scale. Then reassessed with drug Paroxetine at week 4 and week 8 . There was a drastic reduction in the prevalence of symptoms in week 8 than compared to week 4 . A significant reduction in body weight was also observed during the study period. Among various side effects, nausea was the prominent risk found during the study.

Conclusion: The present study demonstrated that paroxetine is effective and well-tolerated for the treatment of various types of anxiety disorder in teenagers with few side effects.

Keywords: Ham-A, Anxiety, Teenage patients, SSRIs

(c) 2020 The Authors. Published by Innovare Academic Sciences Pvt Ltd. This is an open access article under the CC BY license (http://creativecommons.org/licenses/by/4.0/) DOI: http://dx.doi.org/10.22159/ijpps.2020v12i7.37792. Journal homepage: https://innovareacademics.in/journals/index.php/ijpps

\section{INTRODUCTION}

Anxiety disorders are the most common group of psychiatric illnesses in children. Anxiety is a blanket term covering several different forms of abnormal and pathological fear. The disorder is frequently accompanied by physiological symptoms such as headache, excessive sweating, muscle spasms, palpitations, and hypertension, which in some cases lead to fatigue and exhaustion. Those affected can also flare up at times of high stress [1]. Anxiety disorders are the most common of mental disorders and affect more than 25 million Americans. But anxiety disorders are treatable and a number of effective treatments are available. Treatment helps most people lead normal productive lives [2]. According to the American Psychiatric Association, anxiety disorders are the most common type of psychiatric disorder. Despite the high prevalence rates of these anxiety disorders, they often are under-recognized and undertreated clinical problems [3]. Anxiety disorders can run in families, suggesting that a combination of genes and environmental stresses can produce disorders [4]. Selective serotonin reuptake inhibitors (SSRIs), serotonin-nor epinephrine reuptake inhibitors (SNRIs), and pregabalin are recommended as first-line drugs due to their favourable risk-benefit ratio, with some differentiation regarding the various anxiety disorders [5]. Serotonin is a chemical neurotransmitter that plays an important role in mood regulation, is one of the key factors in a lack of balance in mood disorders such as anxiety and depression. SSRI has serotonin reuptake reduction in specific neurons, causing an increase in the brain serotonin and reduce the symptoms of mental health disorders. SSRI, in general, are safer than others but have their own side effects, which are usually sexual, metabolic, and gastrointestinal [6]. The HAM-A was one of the first rating scales developed to measure the severity of anxiety symptoms and is still widely used today in both clinical and research settings. The scale consists of 14 items, each defined by a series of symptoms, and measures both psychic anxiety (mental agitation and psychological distress) and somatic anxiety (physical complaints related to anxiety [7]. A total of 44.9 people suffered from anxiety. In most of the study among gender, Women were suffered from various anxiety disorders compared to Men. The main objective of the study is to investigates the effects of paroxetine in anxiety disorder among teenagers in South India population using Hamilton Anxiety Rating Scale (HAM-A).

\section{MATERIALS AND METHODS}

A prospective observational study was conducted at the Outpatient Psychiatry ward in Sri Ramachandra medical college and Research Institute (SRMC and RI), Porur, Chennai, Tamilnadu for the period of 6 mo. The study protocol was approved by the institutional Ethics Committee of Sri Ramachandra Institute of Higher education and Research, Deemed to be University, Chennai, Tamilnadu, India (CSP/19/Nov/81/394). After getting written informed consent or and assent from the patients and caretakers. The study population includes both sexes, age group between 13 to 19years, Teenage patient with an anxiety disorder and with all co-morbidities, Teenage patient receiving Paroxetine for anxiety disorder were included and Patient with other Psychiatric conditions like schizophrenia, Bipolar disorder, Depression, ICU'S patients, Patient with the previous history of hypersensitivity to SSRI and had serotonin syndrome, Patient with severe anxiety disorder requiring inpatient admission were excluded. Adverse drug reactions and its severity for drug paroxetine were assessed by using WHO causality scale. The sample size was determined by using epi software 2.1.3 version with confidence interval $95 \%$. The calculated sample size was 84 . Hence with $10 \%$ of attrition rate. The sample size was found to be 92 . The collected data were analyzed with IBM. SPSS statistic software version 60 . To describe about the data, descriptive 
statistics mean and standard deviation (SD) were used. To find the significant difference between the multivariate samples, repeated measures of ANOVA was used. In the above statistical tool the probability value 0.05 is considered as significant level.

\section{RESULTS}

A total of 92 teenage patients with an anxiety disorder was recruited as per the selection criteria and followed up during the study period. 8 patients were lost the follow up at $12^{\text {th }}$ week for various reasons such as, withdraw consent (5), could not be reached (1), and relocated (2). Finally, 84 patients completed the study and were assessed using Hamilton Anxiety Rating Scale (HAM-A) and weight was observed before and after the treatment. Out of 84 teenage patients, 53 were female and 31 were male. The study includes teenage patient's age between 13 and 19 (18 male and 41 female). More number of patients found in age between 14 and 17. The study was assessed using HAM-A scale which includes 14 items each defined by a series of symptoms. Each item was rated on a 5 point likert response. Each item is scored on a scale of 0 (not present) to 4 (severe), with a total score range of $0-56$, where $<17$ indicates mild severity, 18-24 mild to moderate severity and 25-30 moderate to severe. Each question from the HAM-A scale was assessed at baseline (Before treatment), and at $4^{\text {th }}$ and $8^{\text {th }}$ week (After treatment) to the patients. From 84 patients 27 patients with generalized Anxiety disorder and Specific phobia (8 male and 11 female respectively) were most observed in this study then Academic difficulty contributed as a reason for most of the anxiety cause in teenage patients (table 1), Followed by School dropouts (11 patients) which also contributed second most reason for the causes of anxiety disorder. The Overall Anxiety score in 84 patients using HAM-A scale was shown in (table 2). Comparison of anxiety severity at Baseline (Before treatment) and week 4 and week 8(after treatment with paroxetine) were shown in (table 3). The prevalence of symptoms at baseline was very severe, then reassessed with paroxetine at week 4 and week 8 . There was drastic reduction in the prevalence of symptoms in week 8 compared to week 4 . The most commonly reported adverse events in this study were nausea, the causality assessment was done by using WHO scale and 21 patients reported nausea during the treatment. dechallenge was positive in 21 (25\%), in which 14 patients were Possible and 07 patients had probable adverse drug reactions according to the WHO scale.

Table 1: Reasons for anxiety disorder observed in the study

\begin{tabular}{|c|c|c|c|}
\hline S. No. & Reason for anxiety disorder & Total no. of patients $(n=84)$ & Percentage (\%) \\
\hline 1. & Fear of other judgments & 4 & 4.76 \\
\hline 2. & Fear of places & 1 & 1.19 \\
\hline 3. & Fear of objects & 2 & 2.38 \\
\hline 4. & Separation of parents & 3 & 3.57 \\
\hline 5. & Separation of caregiver & 2 & 2.38 \\
\hline 6. & Academic difficulty & 18 & 21.42 \\
\hline 7. & School dropouts & 11 & 13.09 \\
\hline 8. & Medical test & 4 & 4.76 \\
\hline 9. & Illness & 4 & 4.76 \\
\hline 10. & Personal relationship & 3 & 3.57 \\
\hline 11. & Job & 3 & 3.57 \\
\hline 12. & Socio-economic needs & 4 & 4.76 \\
\hline 13. & Substance abuse & 10 & 11.90 \\
\hline 14. & Physical abuse & 3 & 3.57 \\
\hline 15. & Personality traits & 2 & 2.38 \\
\hline 16. & Imaginary creatures & 3 & 3.57 \\
\hline 17. & Genetics & 3 & 3.57 \\
\hline 18. & Unknown & 4 & 4.76 \\
\hline
\end{tabular}

Table 2: Overall anxiety score in 84 patients using the ham-a scale

\begin{tabular}{|c|c|c|c|c|}
\hline S. No. & Conditions & Baseline (BT) & Week 4 (AT) & Week 8 (AT) \\
\hline 1. & Anxious mood & 279 & 171 & 145 \\
\hline 2. & Tension & 249 & 217 & 136 \\
\hline 3. & Fears & 266 & 177 & 112 \\
\hline 4. & Insomnia & 248 & 166 & 108 \\
\hline 5. & Intellectual & 245 & 140 & 91 \\
\hline 6. & Depressed mood & 249 & 200 & 94 \\
\hline 7. & Somatic complaints-muscular & 145 & 145 & 93 \\
\hline 8. & Somatic complaints-sensory & 138 & 128 & 80 \\
\hline 9. & Cardiovascular symptoms & 154 & 144 & 88 \\
\hline 10. & Respiratory symptoms & 147 & 135 & 94 \\
\hline 11. & Gastrointestinal symptoms & 176 & 150 & 97 \\
\hline 12. & Genitourinary symptoms & 179 & 159 & 112 \\
\hline 13. & Autonomic symptoms & 186 & 164 & 86 \\
\hline 14. & Behaviour at interview & 205 & 182 & 128 \\
\hline
\end{tabular}

BT-Before treatment AT-After treatment

Table 3: Comparison of anxiety severity at baseline, week 4 and week 8

\begin{tabular}{lllll}
\hline S. No. & Severity & Total no. of patients (n=84) & Week 4 (AT) & Week 8 (AT) \\
\cline { 3 - 5 } & & Baseline (BT) & 3 & 14 \\
\hline 1. & Normal & 0 & 8 & 34 \\
2. & Mild & 1 & 23 & 33 \\
3. & Moderate & 18 & 33 & 3 \\
4. & Severe & 65 & 17 & 0 \\
5. & Very severe & &
\end{tabular}

BT-Before treatment AT-After treatment 


\section{Statistical inference}

A repeated measure of ANOVA with sphericity determined that mean HAM-A score differed statistically significant between time points $(\mathrm{F}(2,166=558.880)=\mathrm{P}<0.001)$. Post hoc tests using the Bonferroni correction revealed that paroxetine for anxiety disorder elicited a reduction in HAM-A score from baseline to week 4 and week 8 of paroxetine $(34.12 \pm 4.75, \quad 27.12 \pm 5.43, \quad 17.43 \pm 5.31$ respectively) Which was statistically significant $(\mathrm{P}<0.001)$. Therefore, we conclude that a paroxetine treatment for anxiety disorder elicits a statistically significance reduction in HAM-A score by week 4 and week 8 .

\section{DISCUSSION}

A prospective observational study was conducted for a duration of 6 mo. This study includes 84 patients treated with paroxetine for various types of anxiety disorder and assessed by HAM-A in the outpatient Psychiatry ward. The prevalence of anxiety disorder in the study was higher in females (61.90\%) than males (38.09\%) which was similar to the study conducted by M. K. C. Nair et al., in which female (63.4\%) are higher than male (36.6\%) [8]. Among 84 teenage patients, 52 were female and 32 were male, the prevalence of anxiety disorder was higher in female than male. A similar study carried out by Angelina et al., out of 91 patients, 54 were female and 37 were male [1]. This study includes a teenage patient's age between 13 and $19(21.42 \%$ male and $48.80 \%$ female). The prevalence of patients with anxiety disorder found in age group between 14 and 17 were high, this result was concordance with study conducted by Borwin Bondelow et al. [9]. Angelina et al., conducted a study on anxiety disorder students whose age ranged from 9-18 y with a modal age of $13 y$, which was similar to this study were patient's age ranged from $13-19 \mathrm{y}$ with a model of $14 \mathrm{y}$ was observed [1]. In this study, about $32.14 \%$ of generalized anxiety disorder and $22.61 \%$ Specific phobia was the most onsets in teenagers; this is concordant with an epidemiological study carried out by Borwin Bondelow et al., social anxiety disorder and specific phobia were high onset in this age group [9]. Academic difficulty (21.42\%) contributes as a reason for most of the anxiety caused in teenage patients, this results were similar to the study conducted by Angela et al. in school student with an anxiety disorder were poor academic performance $(34.06 \%)$ was the reason for cause [1]. Hamilton anxiety rating scale scores were significantly decreased over week 8 with paroxetine in this study which correlates with a study conducted by Tae-Suk Kim et al,, compared 51 paroxetine with Venlafaxine extended-release given over $8 \mathrm{w}$ for patients between 18 and $65 \mathrm{y}$ assessed using HAM-A scale where scores significantly decreased over week 8 with paroxetine [10]. Tae-Suk Kim et al., assessed the efficacy of paroxetine with the HAM-A and CGI-S scale at the baseline, week 1, week 4 and week 8 . In this study, paroxetine efficacy assessed with HAM-A scale at the baseline, week 4 and week 8 [10]. The most commonly reported adverse events in teenagers were nausea, and the risk assessment done by using WHO scale, but in Gulseren et al. conducted a comparative study on fluoxetine and paroxetine in adults with T2DM, adverse events reported were insomnia and anxiety [11]. Paroxetine is significantly effective in social anxiety disorder in this study and it was concordance with study carried out by Wagner et al. in young people and adolescents [12]. Repeated measures of ANOVA showed a significant reduction effect on time.

\section{CONCLUSION}

The study demonstrated that paroxetine is effective and well tolerated for the treatment of various types of anxiety disorder in teenagers. There was no significant weight gain was observed in patient during the study. The clinical applicability of paroxetine showed greater promise in treating anxiety in teenagers with fewer side effects.

\section{LIMITATION}

Need to study from large sample size and the drug paroxetine should be compared with other SSRIs for better anti-anxiety effect and high safety profile in teenagers

\section{FUNDING}

Nil

\section{AUTHORS CONTRIBUTIONS}

Dr. S. Karthik, Dr. C. Padmapriya conceived the idea, developed the proposal, and wrote the manuscript. S. Sindhu, S. Navaneethakrishnan, S. Sasikumar collected, analyzed and interpreted the data.

\section{CONFLICT OF INTERESTS}

The authors declare no conflict of interest regarding the content of this article.

\section{REFERENCES}

1. Angela I, Frank briggs, EAD Alikor. Anxiety disorder amongst secondary school children in an urban city in Nigeria. Int J Biomed Sci 2010;6:246-51.

2. Psychiatrists American psychiatric association. Available from: https://www.psychiatry.org/patients-families/anxietydisorders. [Last accessed on 07 Apr 2020]

3. Nita $\mathrm{V}$ Bhatt. Medscape. Available from: https://emedicine.medscape.com/article/286227-overview. [Last accessed on 07 Apr 2020]

4. Ranna parekh. Psychiatric. Available from: https://www.psychiatry.org/patients-families/anxietydisorders/what-are-anxiety disorders. [Last accessed on 07 Apr 2020].

5. BorwinBandelow, Leo Sher, Robertas Bunevicius, Eric Hollander, Siegfried Kasper, Joseph Zohar, et al. Guidelines for the pharmacological treatment of anxiety disorders, obsessivecompulsive disorder and posttraumatic stress disorder in primary care. Int J Psychiatry Clin Practice 2012;16:77-84.

6. Mehdi Sayyah, Fakher Rahim. Comparing the effect of secondgeneration antipsychotics versus selective serotonin reuptake inhibitors in refractory obsessive-compulsive disorder: a systematic review of the past, present, and future clinical trials. Asian J Pharm Clin Res 2017;10:150-16.

7. Hamilton M. The assessment of anxiety states by rating. $\mathrm{Br} \mathrm{J}$ Med Psychol 1959;32:50-5.

8. Nair MKC, Russell PSS, Mammen P. A dad 3: the epidemiology of anxiety disorders among adolescents in a rural community population in India. Indian J Pediatr 2013;80 Suppl 2:144-8.

9. Borwin Bandelow, Sophie Michaelis. Epidemiology of anxiety disorders in the 21st century. Dialogues Clin Neurosci 2015;17:327-35.

10. Tae Suk Kim, Chi Un Pae, Su Jung Yoon, Won Myong Bahk, Jun Won Tae, Jeong Ho Chae, et al. Comparison of venlafaxine extended-release versus paroxetine for treatment of patients with generalized anxiety disorder. Psychiatry Clin Neurosci 2006;60:347-51.

11. Gülseren L, Gülseren S, Hekimsoy Z, Mete L. Comparison of fluoxetine and paroxetine in type II diabetes mellitus patients. Arch Med Res 2005;36:159-65.

12. Wagner KD, Berard R, Stein MB. Paroxetine improves social anxiety disorder in children and Adolescents. Arch Gen Psychiatry 2004;61:1153-62. 